\title{
reGREENeration of Historic Cairo. Hara al-Nabawiya and Bayt Madkour in al-Darb Al-Ahmar
}

\author{
Natalia Ramírez \\ Brandenburg University of Technology, Germany / Alexandria University, Egypt \\ natalia.ramirez.arango@gmail.com
}

\author{
Alaa El Habashi \\ Menoufia University / Alexandria University, Egypt \\ alaa.elhabashi@gmail.com
}

\begin{abstract}
In historical contexts like Cairo with rapid informal growth, the role of open spaces as Haras or courtyards are no longer seen as components of a very particular ecological system or centres of social encounters. The demand for housing and the relative costbenefit has unleashed vast and illegal densification in height within neglected and dilapidated urban areas, where any available space represents an opportunity for investments and to accommodate the immediate needs.

The research explores the on-going disfiguration in the al-Darb al-Ahmar of Historic Cairo, and investigates the results along with the current international calls for the respect of the integrity of the environmental and socio-economic characteristics of tangible and intangible heritage in the World Heritage Site. The objective is to profit from the remaining courtyards of historic buildings and Haras spaces in Historic Cairo to propose urban strategies that would restore such historic attributes, reformulate an ecologically passive urban fabric and generate means for community development. This proactive approach is hopefully a necessary step for stopping the demolition, deterioration, and obsolescence of districts of high historical values.
\end{abstract}

Keywords: historic Cairo, green corridors, revitalization, public spaces, courtyards

To cite this article:

Ramírez, N., El Habashi, A. (2020). reGREENeration of Historic Cairo. Hara al-Nabawiya and Bayt Madkour in al-Darb Al-Ahmar, The Journal of Public Space, 5(I), 5I-74, DOI 10.3289I/jps.v5il.I25I

This article has been double blind peer reviewed and accepted for publication in The Journal of Public Space. (c) (1) \$ This work is licensed under a Creative Commons Attribution - Non Commercial 4.0 International License https://creativecommons.org/licenses/by-nc/4.0/ 


\section{Introduction}

Green open-spaces within dense cities play a vital role in sustainable urban development by their environmental, recreational, and socio-economic benefits. This fact is evident, in ancient districts, like those of Historic Cairo (the chosen case of study), where the initial urban fabric respected the local environment through a thoughtful pattern of open spaces. Indoor and outdoor spaces were carefully designed and positioned to fulfil that role. For instance, while narrow and non-aligned alleys remain in shade with lower temperatures during the day as an effective climate control tool, the orientation of courtyards that, with the association of wind-catchers, upper arcades sitting area (maq'ad) and private annexed gardens, allow the north breeze to flow and to create an internal natural cooling system. North-south public open axes are continuous within the city fabric to profit the most from that north breeze, while most of the east-west alleys are short, interrupted and usually with dead-ends limiting the possibility to hot and nonpreferable winds that usually carry the desert sand. (El-Habashi \& all, 20I8) In that respect, the buildings' courtyards are environmental regulators at the micro levels, and are related to a city-scale ecological system set by its through fares, streets and alleys. The association between social activities, religious beliefs and the economic status defines the spatial organization of the open spaces in a neighbourhood. The same narrow streets that create an enjoyable environment together with attached houses and dead-end passages (zuqaq, or alley), facilitate social integrity, security, sense of belonging and collective defence system. Recognizing socio-economic differences from an interrupted street façade where each building appeared as an integral part, is almost impossible. In contrast, the size and quality of internal open spaces usually reflect the wealth and the status of the buildings' founders. In cities with Muslim communities, the dense and the organic nature of the urban fabric does not obstruct human flow and mobility, but instead it allows intimate interaction between relatives, friends, as well as making markets, and facilities in close proximities.

In historic Cairo, and due to the rapid unplanned growth, the historical fragile urban and social structures are being disfigured and are at risk of disappearing. The residential neighbourhoods are intruded with commercial activities and invaded with high-rise buildings, congested motorized vehicles, noise, pollution, and predominant lower-class population. The balance that characterized the historical social pattern is no longer respected. Each residential unit is now a self-sufficient bubble to accommodate basic needs in the minimum possible cost and quality. Natural ventilation or illumination are considered luxury and unnecessary. Although the urban morphology remains almost intact with the exception of few pockets, the exquisite medieval facades, wood-lattice windows (masrabiyya) are alienated within a jungle of unfinished red-brick and reinforced concrete towers.

In accordance with the World Heritage Convention a sustainable development perspective should integrate environmental, social and economic dimensions holistically, with none to predominate over the other. (UNESCO, 2015) It is thus necessary in the context of Historic Cairo to improve the living conditions while boosting local economies, preserving values and significant features, transforming fixed structures into resilient and flexible spaces which can be able to evolve and adapt to rapid urbanization and contemporary needs. These challenges require both bottom-up and top-down strategies to make remedies feasible and integral. 
This research analyses the urban morphology chronologically to detect and indicate changes in the network of open spaces and to explore the possibilities to connect between the remaining ones, especially courtyards and Haras. It selects the area of Bayt Madkour and Hara Fatema al-Nabawiya in al-Darb al-Ahmar as a case study to formulate urban guidelines that would revitalize and activate the ecological system while improving and celebrating historical, social and environmental values. For that, this study poses two primary questions:

- How to re-signify courtyards as part of an ecological system within historical contexts with rapid informal growth?

- What is the role that private and public open spaces can play for the development of communities living in historical areas?

The hypothesis is that if courtyards are physically related to the public space, functionally articulated for the community needs and developed dependent on the character of the site, they can be catalysts for the possible resignification. If these spaces become a fundamental part of the life of locals, economic and social value can regenerate. Subsequently, the stopping of the densification and demolition of historic courtyard building typology trends would be a community mandate. The hypothesis also considers the proposed approach as means for setting organic green corridors within the urban fabric that can then restore the interrupted ecological structure.

The hypothesis profits from the Haras as being traditional and specific urban spaces that interrelate between public, semi-public and private domains. It is an urban and social system whereby the public open spaces become extensions of the interior private courtyards, and the thresholds become the ground for social and economic interactions.

\section{New Approaches in Managing Historic Urban Landscape (HUL)}

"...the city is not a static monument or group of buildings, but subject to dynamic forces in the economic, social and cultural spheres that shaped it and keep shaping it..."

Irina Bokova

Director-General of UNESCO at the World Urban Forum

(Naples, 20I2)

In 201 I the proposal for a recommendation on the Historic Urban Landscape (HUL) was accepted by UNESCO as an innovative approach for preservation and management of historic cities. The new approach is based on both cultural and natural values, thus encountering beside historic buildings, contemporary architecture, open spaces and above all local communities. The HUL seeks to increase the sustainability of planning and design interventions, (UNESCO, 20I3) and extends the concern directed exclusively to heritage sites to encounter tools and resources that tackle the profile of the city, its urbanized environment, topography, visual axes, traditional architectural typologies, open spaces, infrastructures, archaeology and contemporary architecture, in addition to cultural values, socio-economic processes and intangible aspects. (UNESCO, 20I5) (Figure I). 


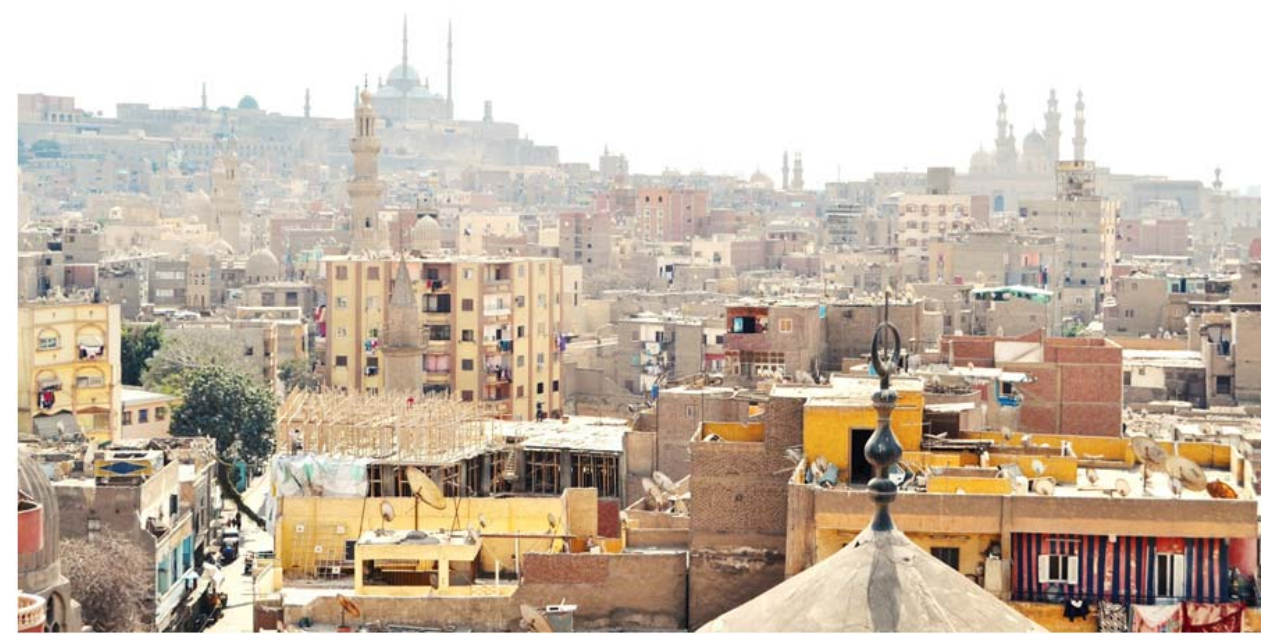

Figure I. Built-Environment of Historic Cairo with the absence of green. Source: Photo taken by the authors.

The interest on sustainable development in historic districts has been extended during the XVII ICOMOS general assembly in 20II, which resulted in 'The Valletta Principles for the Safeguarding and Management of Historic Cities, Towns and Urban Areas'. In parallel, the ONU-HABITAT created the 2030 Agenda and Sustainable development goals (SDGs) as a roadmap to make cities more inclusive, resilient and fight against poverty and inequality, and considered culture and heritage as the spine of the sustainable urban development. Those recent international concerns are of a particular interest to this research as they present, especially in the case of Valleta charter, principles and tools such as the implementation of networks of green corridors, and the respect of the balance between the natural values while transforming historic areas. Those principles and tools have been already conceptualized for the context of Historic Cairo. (ElHabashi \& all, 2018).

\section{Green Corridors for Historic Cairo}

Green corridors are proposed to mitigate negative effects of the built environment while connecting fragmented green spaces with ecological systems to enhance biodiversity, human experience, and climate conditions within the urban landscapes. Due to the urban sprawl phenomenon, green areas are under threatened and the expansion of city structures left behind small green patches amongst buildings. (ADAPT, 2015). Green corridors proved to have positive effects on social, ecological and financial aspects as they guarantee decent environmental qualities, recreational activities, spaces for community gathering and interaction. They also have fundamental role in improving urban ventilation, reducing heat island effect, mitigating air pollution, and lessening the vulnerability to floods and animal species dispersal. They also contribute to restoring the original passivity of urban landscapes, which in the long term represent a substantial economical saving. (Rasidi, 20I4)

Several success projects of green corridors can be cited here. The case of Bratislava in rehabilitating several parks and introducing roof gardens with capabilities to capture water from excess of irrigating systems is to be recognized. Another case is the 
rehabilitation of the Highline of New York transforming an abandoned historic railway track into a public green space that includes several recreational activities enhancing the relations with the surrounded buildings and communities. 'Corredores verdes, conectando naturaleza y comunidades' in Medellin, Colombia, is a third example where integrating large green public spaces have promoted social reconciliation. (ADAPT, 20I5). In the case of Historic Cairo, open public spaces are scarce while the recent introduction of new gardens, such as al-Azhar Park and others is not part of a holistic environmental vision. In addition, managing the historic city through the HUL approach is still a long way to go, since the scale is now metropolitan where tangible and intangible heritage are not of a primary concern for local authorities.

\section{"Hara" and "Courtyard" in Historic Cairo}

Living in Cairo in the XVII-XVIII centuries was a completely different experience since houses and quarters were connected one to other, without affecting the hierarchy and level of privacy of each. The basic daily needs lacking in houses such as obtaining drinking water from public fountains, bathing in public baths, and cooking in their furnaces, mandated a constant interrelation between the households and the neighbourhood public facilities. Even if large houses of elite families of beys', emirs, major traders, and religious leaders of the time contain some of those facilities, which were of reduced sizes that mandated the users to still rely on public facilities.

Conversely, the houses of craftsmen, merchants and finally the unskilled workers were of reduced sizes that would not allow spaces for common facilities to be encountered. (Hanna, 199I)

Courtyard houses were those of the elite families. They were usually positioned within the centres of urban neighbourhoods blocks. The humble exteriors of such houses were of similar architectural characters of their surrounding fabric of lesser units, thus often not indicative of what lies behind them of open spaces and luxury. They are set within continuous streetscapes of attached buildings without major distinction. Since those houses are the centre of the activities of most of the inhabitants of the neighbourhood, the central open spaces were availed to them at different occasions, frequencies and various levels of accessibility. The courtyard with its fountain in the middle, a main sitting area the taktabush and a Maqa'ad at the upper floor overlooking it was the centre of the house as well as of the entire neighbourhood. What appears to be a private central open space was in fact used at various capacities and different times as a space where all the neighbourhood interacts (Figure 2).

Availing such central space did not affect the privacy of the elite families. These large houses had special spatial organization for guests, and family men and women, the Salamlik and Haramlik. The function of these open spaces goes beyond the described social spheres. With their northern, or rather north eastern, orientation, they became an element of the climate control that allows north winds flood in and refresh the ambiance. (El-Habashi, 2019) The interaction within those large courtyards was certainly appreciated by the common public, whose houses entail only light wells (manwar) a

\footnotetext{
${ }^{1}$ The governor of a district or province in the Ottoman Empire.
} 
vertical shaft-like space that provide slim light and limited ventilation to the interior of their apartments (Zaky, 2009).

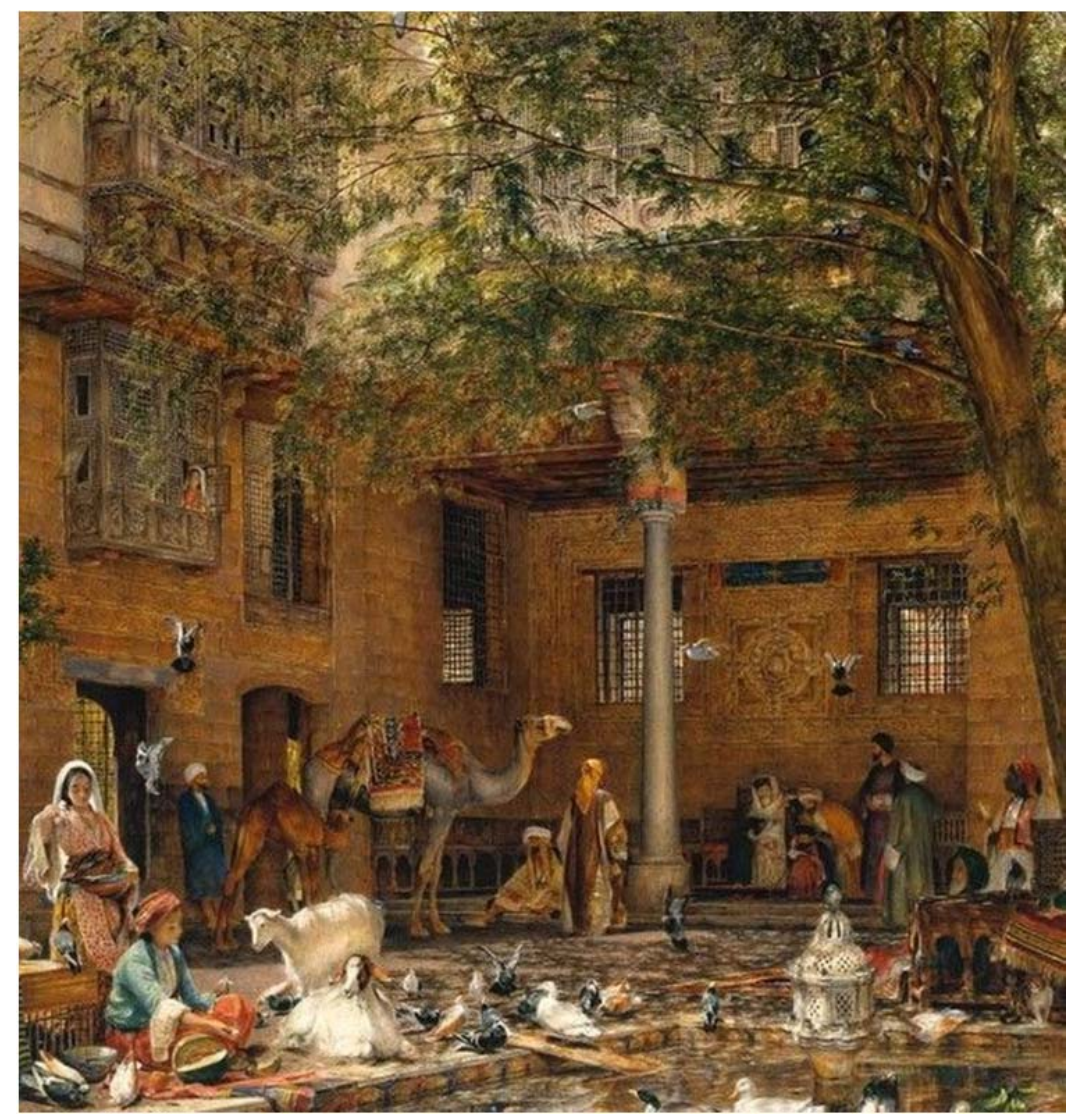

Figure 2. Courtyard life in Cairo. Source: Watercolor by Walter Tyndale (I855-1943).

The permitted accessibilities to such luxurious spaces were complemented with the constant availability of the closed streets (zuqaq) and the semi-private spaces located outside the house, haras. Those semi-private spaces served for a specific neighbourhood whose inhabitants were usually of the same origin, the same religion and sometimes the same profession. Haras were often named after that common feature, and administered by the residents with little municipal infliction. In most cases, a secured gate towards the street would be the only entrance to hara. (Figure 3) The haras, had developed the collective life of the quarter and allowed the inhabitants to have close relationships, with a hierarchical organization of leaders to solve collective issues. (Hanna, 1991). They, therefore, played important complementary roles to the courtyard of the elite houses. They were characterized by being relatively small size open spaces consisting of deadend streets with no fixed commercial activities. Their length varies from 40 to 80 meters long with 3 to 4 meters wide and usually served over a hundred families (Zaky, 2009).

This research explores the interconnected roles of the haras and the courtyards of the elite houses in the existing urban fabric of Historic Cairo after it has been utterly disfigured. It employs the concepts and principles of HUL as well as means of sustainable development for historic districts developed by ICOMOS in response to the SDGs. It 
focuses on a selected case study to exemplify the needs to consider and respect the particularities, either historic or contemporary, in shaping approaches to remedy disfigurations. The analyses are divided in three categories: the urban grain, the current social morphology of the Haras, and the network of open spaces (haras/courtyards).

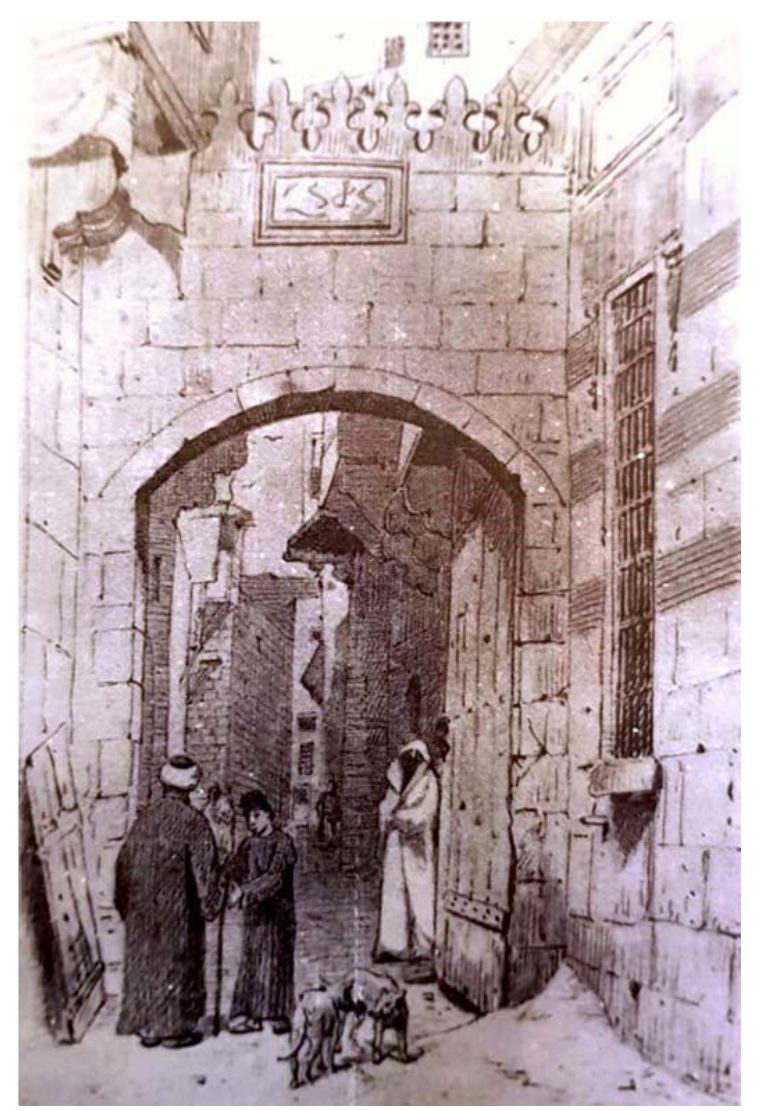

Figure 3. Hara gate in historic Cairo. Source: Hanna Nelly. Habiter au Caire. Aux XVII et XVIII siécles. p. I63.

These were based on a comparison between the current conditions and those of the 1930's as captured in the then cadastral maps of the city. Such analyses led to the formulation of physical, social, economic and political rehabilitation guidelines inspired and based on theoretical principles. ${ }^{2}$

The case study area was chosen for being a wide and diverse urban fabric that entails tangible and intangible values while meeting the following criteria:

- Preserves the historic urban morphology and the traditional spatial configuration of open spaces as (Hara, Darb, and Zuqaq).

- Encloses a large variety of valuable buildings including those of courtyards typology.

- Entails authentic intangible heritage (crafts, religious and social rituals, etc...)

- Represents the World Heritage outstanding value (based on the 2I4 UNESCO report), but subjected to threats of height densification and the rise of incompatible buildings.

\footnotetext{
${ }^{2}$ Specially the Valletta Charter adopted by ICOMOS in 2011
} 
The selected case study shown above is crossed transversely by Bab-Elwazir street, where several outstanding monuments are standing, Al Maridani Mosque, Bayt Razzaz and many Mausoleums and Rab's (traditional duplex buildings). (Figure 4) This main axis is interlinked with secondary paths which consequently lead to dead-rend alleys. The area is part of an urban fabric that exemplifies the hierarchy of open public spaces each with its own level of privacy. This rich context is unfortunately one of the most threatened areas in Historic Cairo due to the continuous demolition of historic structures and the construction of high rise isolated buildings instead rupturing the unity of the urban fabric.

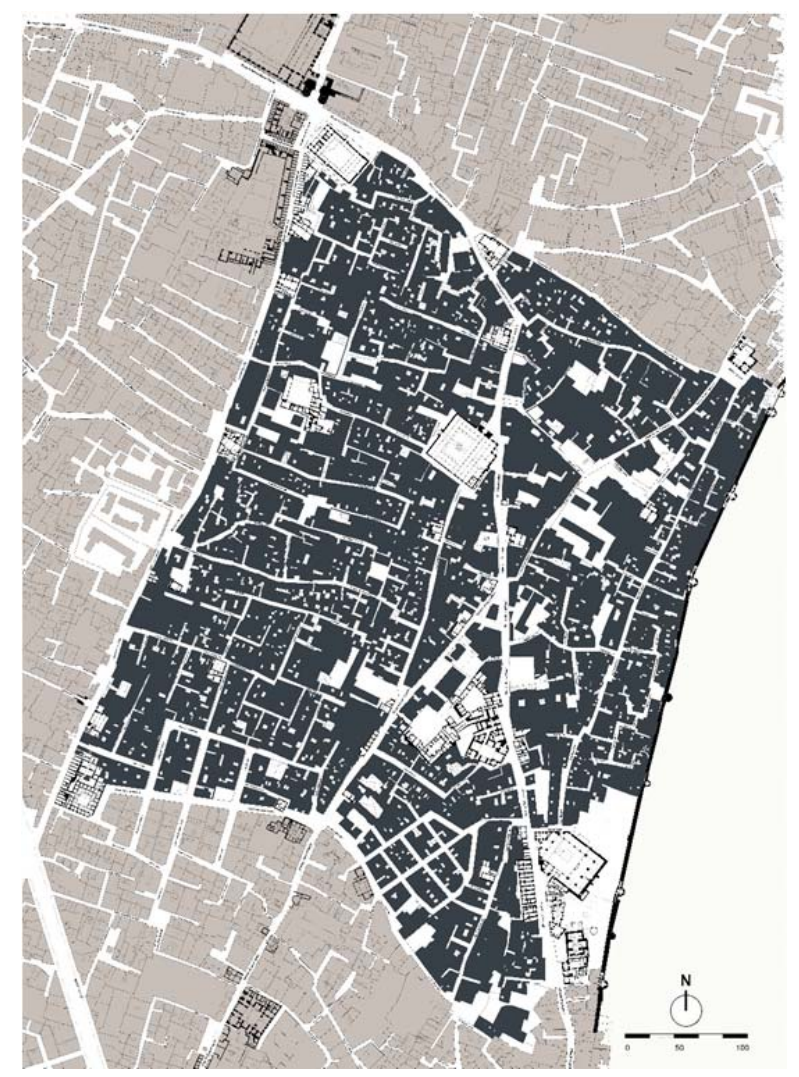

Figure 4. Study case area with building declared as monuments (by the authors in 2019 based on Warner, 2005).

\section{The haras today}

The comparison analyses between the 1930's map of the case study area and the conditions today, (figure 5) show that there were 26 Haras or quarters that remained almost unchanged. However, some of the main streets or semi-private spaces have been extended to connect between them disrupting the exclusiveness of the set fabric for each. The shape of the original streets is mainly organic and zigzagged, with one or maximum two entrances to the hara, a pattern that was modified with the connective branches that appear in the existing situation. Moreover, it is noticeable that in some specific pockets, encircled in the map below, new types of fabric replaced the historic ones. The most obvious recent juxtaposition is the one of Hara al-Yakaniya where a new grid of linear streets stands out from the rest. 

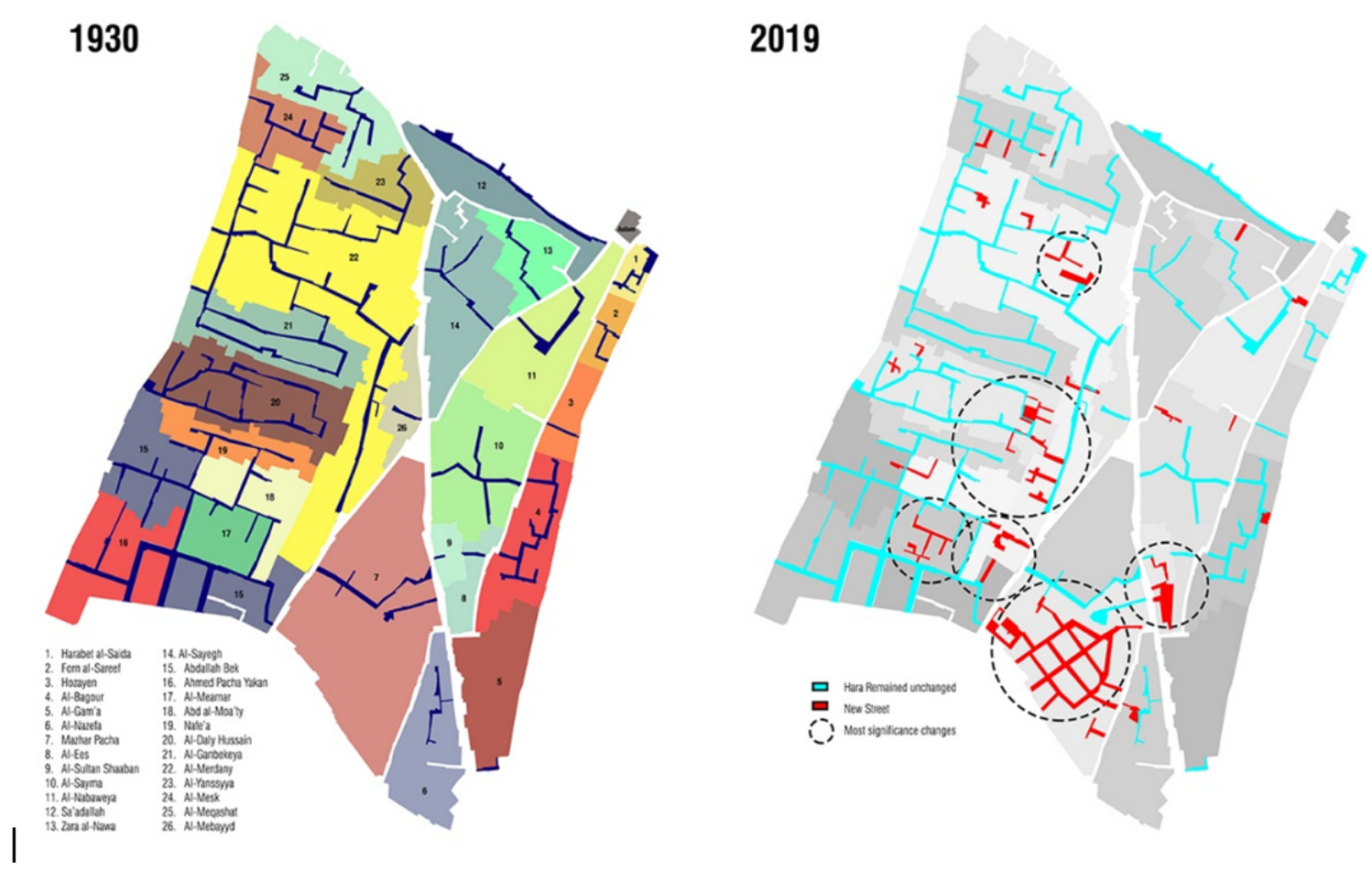

Figure 5. Social and spatial configuration of Haras (1930 and 2019), (the authors based on cadastral map).

The open space of the hara is defined by the width of the street, the length and the characteristics of the buildings that enclosed them. Three different types were identified. (Figure 6) The hara that remains original has the disposition of historic buildings creating a hierarchy for pedestrians to get to the entrance of the space, together with a gate or passage under a sabat (a traditional built fabric that crosses the public space on high levels). The opposite occurs in the new hara, where the space is straight and wide enough to accommodate cars and surrounded by 4 to 5 story buildings. An example is "Harat Mazhar" shown in middle photograph of figure 6. The last type is the one that preserved its original spatial urban configuration but whose built fabric was replaced with incompatible buildings (Figure 6 to the right). While the width of the street was preserved, the heights of the newly constructed buildings utterly make the environment unbalanced. It is noticeable that among the three types the last one provides the least amount of sunlight reaching the public spaces.

The second comparison is between the urban grains. Figure 7 illustrates the drastic changes in the built masses and voids. It indicates the locations of the most significant variations within the study area. In 1930's, the urban fabric had a balance relation between open spaces and built-up areas characterized by organic and irregular blocks with several inner courtyards, oriented to the northeast side. Conversely, by the year of 2019 the urban grain is utterly modified. Urban blocks were transformed onto dense units with the streets as the only open spaces. Areas with relatively large open spaces are mostly vacant or residual land that differs completely from the original urban composition. 


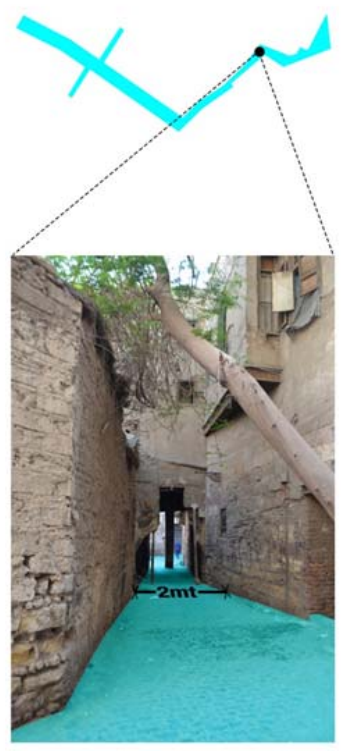

Original Hara remained unchanged
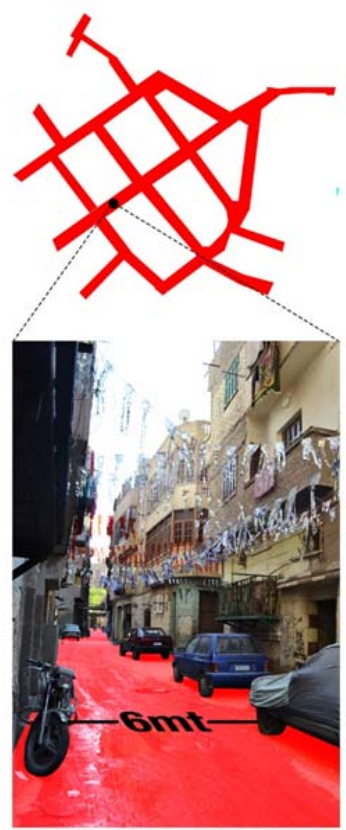

New typology of Hara

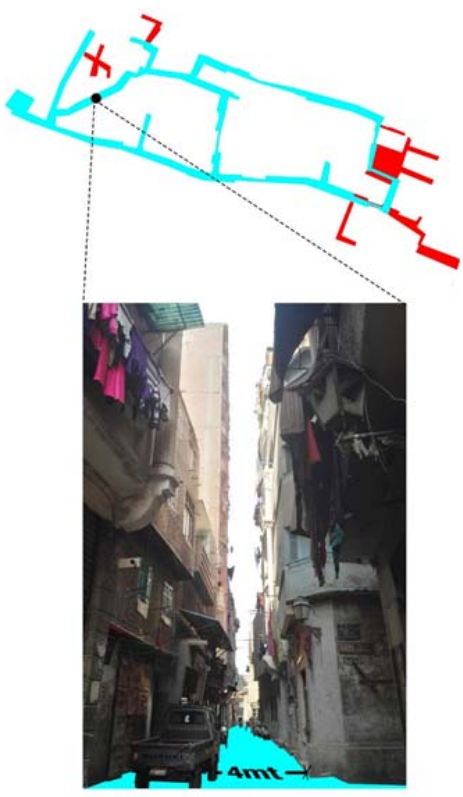

Original Hara modified in scale

Figure 6: Haras typologies (the authors).
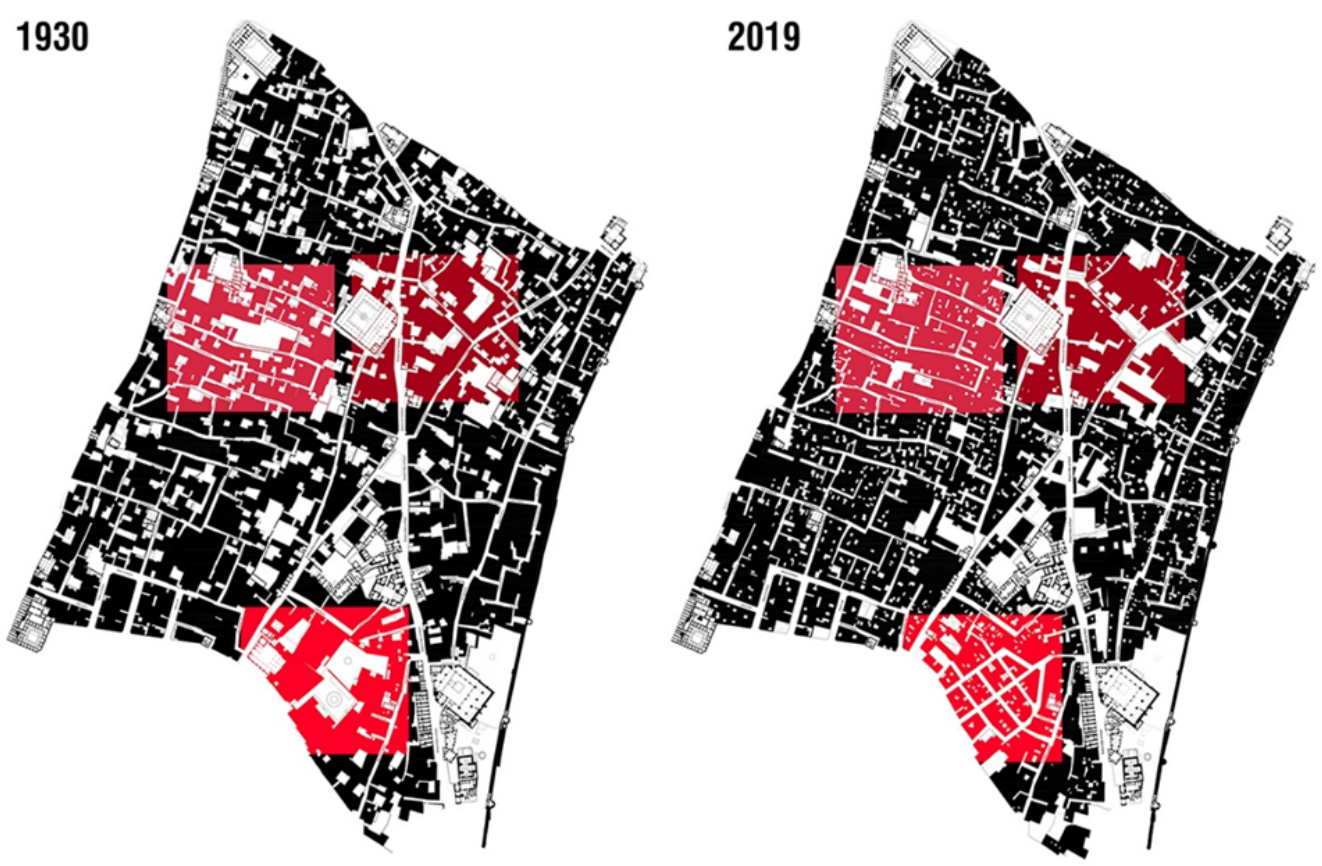

Figure 7. Urban grain (1930 and 2019) (the authors based on cadastral maps and field survey).

The three areas of dramatic changes are: Bayt Yakan area, Qaytbay palace surroundings and Bayt Madkour and Hara el Nabawiya. The first and the most remarkable variation of the urban fabric can be described as the completely or partially fill-up of the traditional courtyards, the demolition of important buildings, among which a Mosque in the North 
West corner, and its replacement by different typologies of housing blocks. The second location is characterized by a longitudinal block were the inner open spaces have been filled in 2019 leaving only little open spaces for the access to the roofs. The third is the most complex one, because even when the relation between open and built is somewhat similar, the distribution of open spaces seems unbalanced and disorganized. The third also entails the variations explained in the first and second conditions. The three new typologies are not aligned to the original, and they left several residual spaces. (Figure 8).
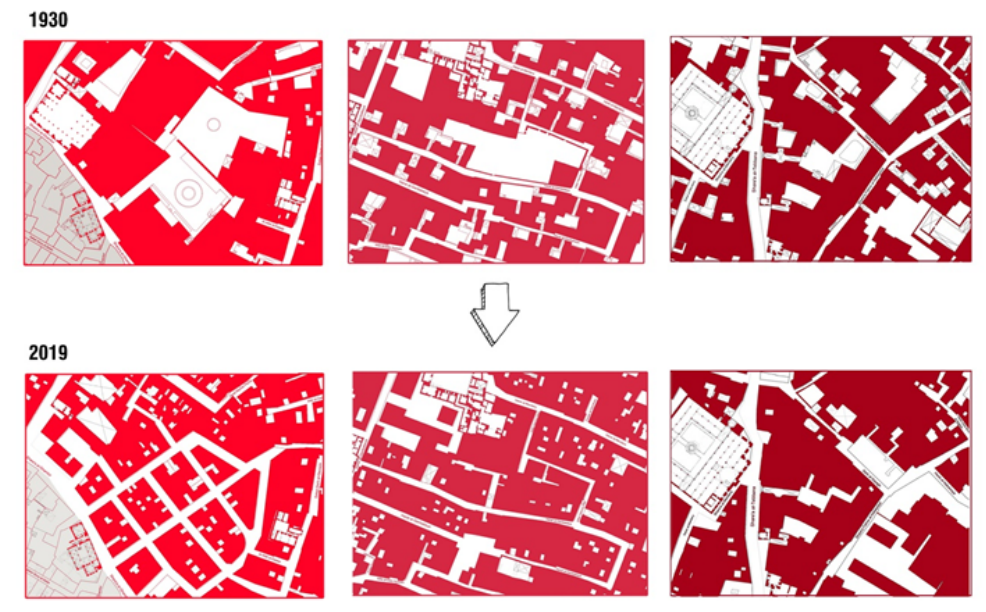

Bayt Yakan area

Qtbay palace surroundings

Bayt Madkour area

Figure 8. Significant morphological changes between 1930 and 2019 (the authors).

\section{Open spaces network}

As for the network of the open spaces, figure 9 shows the size of open areas that has been reduced considerably. It seems evident that open spaces and greeneries available within the area were found in the 1930's map within the buildings' courtyards. In 1930, these spaces constituted a pattern of a particular disposition repeated throughout the area. However, with the disappearance, modification or reduction of courtyard houses, this pattern disrupted with isolated open spaces spread amongst the site. The most significant difference between these two periods is the new green Al Azhar Park introduced in 2005. The Park, although atypical of the traditional form and configuration of open spaces, represents an ecological opportunity that can counterbalance the disappearance of the inner greeneries.

The courtyards that still exist can be categorized in three types as in figure 10. The first two are modified by either being partially built-up in the case of Bayt Madkour, or dramatically reduced in size as in Bayt Yakan. The one that preserves the original size is exemplified by Bayt al-Razzaz. In all cases the orientation of the spaces is north east and the shape is rectangular or trapezoidal. Figure 10 shows the state of condition of the buildings that enclosed these spaces. Those of Bayt al-Razzaz and Bayt Yakan are restored, and Bayt Madkour's is abandoned. Some traditional elements are preserved such as the taktabush, the mashrabiyias, the fountains, vegetation and the balconies overlooking north (maq'ad). 
1930

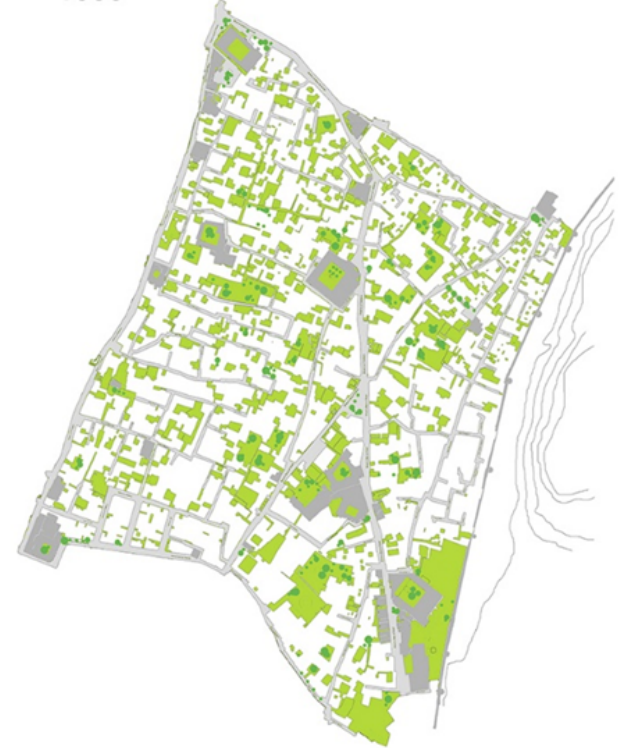

2019

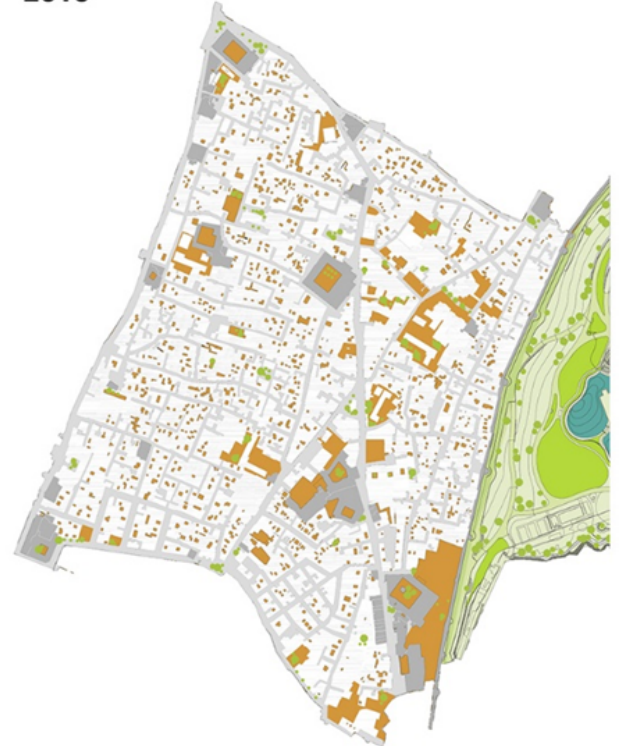

Figure 9. Open spaces network (1930 and 2019) (the authors based on cadastral maps and survey).

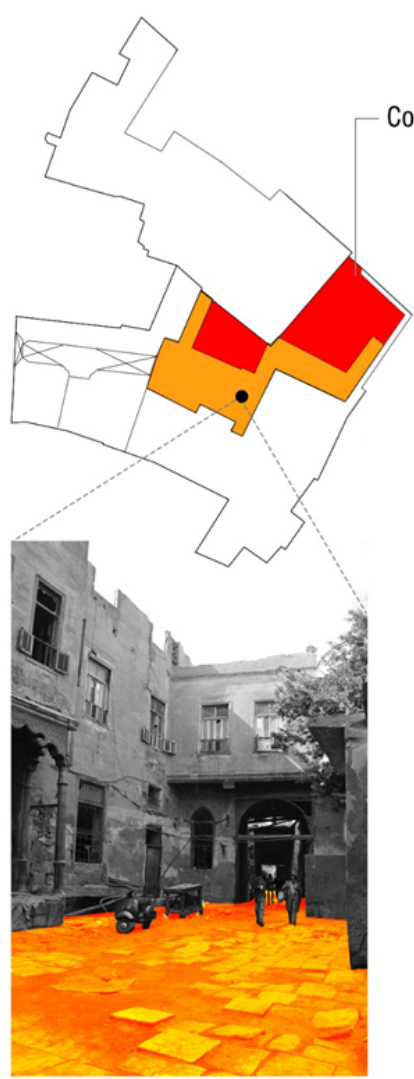

Bayt Madkour
Courtyard area built-up

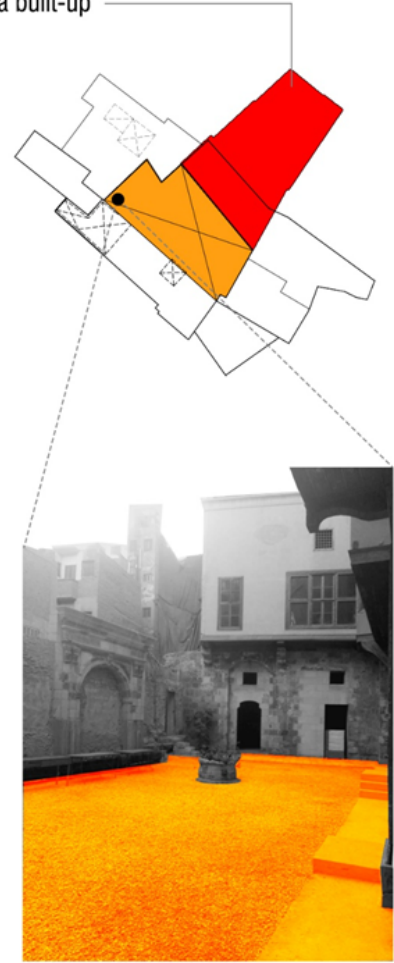

Bayt Yakan
$\circlearrowleft^{N}$

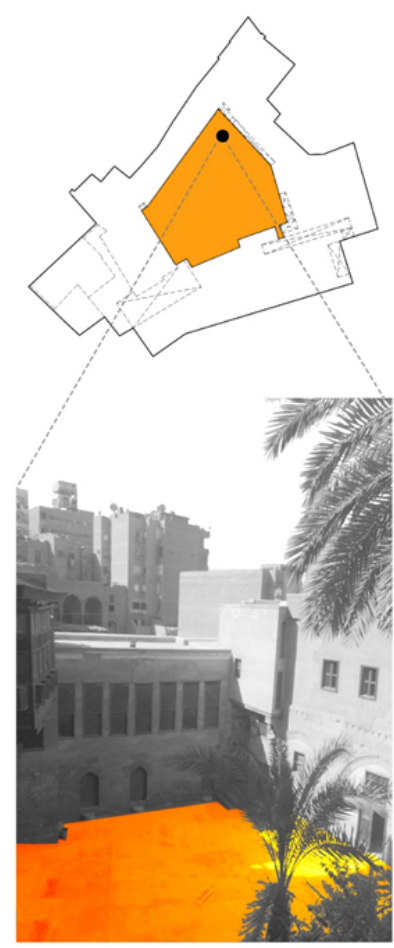

Bayt Razzaz

Figure 10. Courtyards existing types. (the authors).

62 | The Journal of Public Space, 5(I), 2020 | ISSN 2206-9658

City Space Architecture / UN-Habitat 


\section{Informal Growths}

This section of the research is to illustrate the three identified typologies of the urban fabric in the case study area. The generated model is based on a comparing the historic setting deduced from historic maps, namely the one drawn by the French at the beginning of the 19th century, with the existing surveyed situation, and with a supposition of the future scenario if current rate of disfigurations is maintained (Figure II).
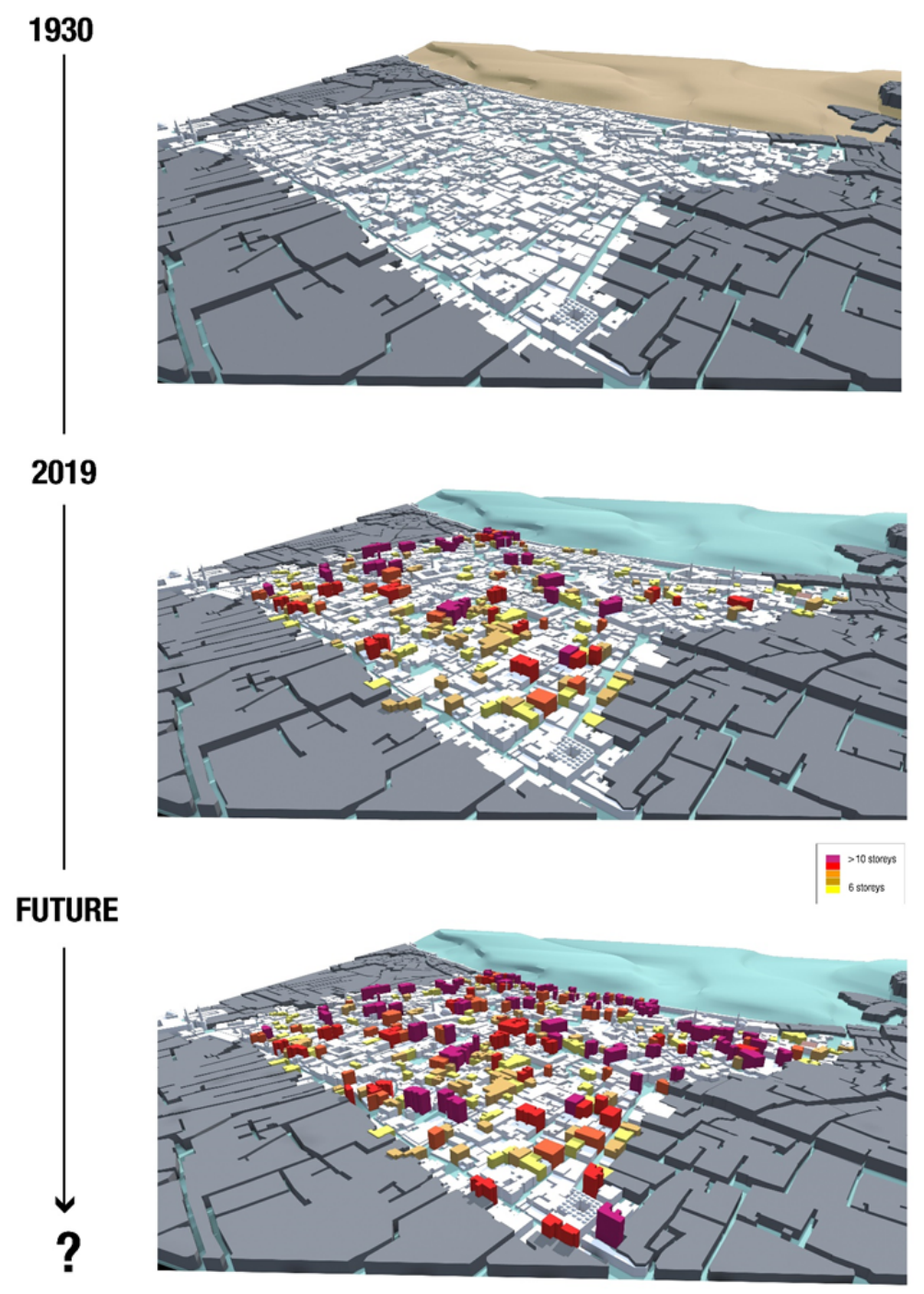

Figure II. Heights of the study case: 1930, 2019, and future scenario. (the authors)

The urban landscape of the beginning of $20^{\text {th }}$ century shows unity in terms of heights which does not exceed the 5 story buildings, except for the minarets and the Mosques' domes. Some eye-bird photos and cadastral plans show a visible deterioration of the area during this period, where many buildings are shown as ruins. The situation is modified in today's figure, where the densification in height by incompatible buildings is evident with volumes that exceed 10 floors. The insertion of a green element and the 
abandoned buildings has stimulated the illegal development of the site. The analysis demonstrates that the disfiguration of the traditional skyline is clear since important landmarks are being hidden and losing its prominence. The provisioned future panorama of this area is alarming if the current trend continues without control and restriction from the Government. Most of the historic or contextual buildings of maximum 5 floors are going to be replaced by towers. The question is whether contemporary shortsighted needs would be loosely left to override thousands of years of history of humankind in this territory.

The crawling of high-rise concrete apartment blocks is an illegal real state trading in small patches of abandoned buildings or lands to offer affordable living units in an area well connected to transportation, business centres, job opportunities and markets of the city. The typology of this informal growth is characterized by one façade building with narrow and dark rooms that shape a unit of 60 to 100 square meters (Gamal, 2016).

Figure 12 shows the impact and magnitude of what this tendency is creating on the site. Ottoman and Mamluk structures are not any more outstanding landmarks in the urban skyline, but rather dwarfed elements surrounded by monsters. The new residential typology is considered a highest threat to the outstanding values of Historic Cairo because it disrupts the balance between human scale and the built environment, it creates unpleasant and dark open public spaces and it fills up open spaces. The result is a grey atmosphere not designed for the human experience, and certainly not sustainable. The dilapidation, abandonment, lack of maintenance of historic buildings and the informal high-rise growths are the main threat of the area and of Historic Cairo.

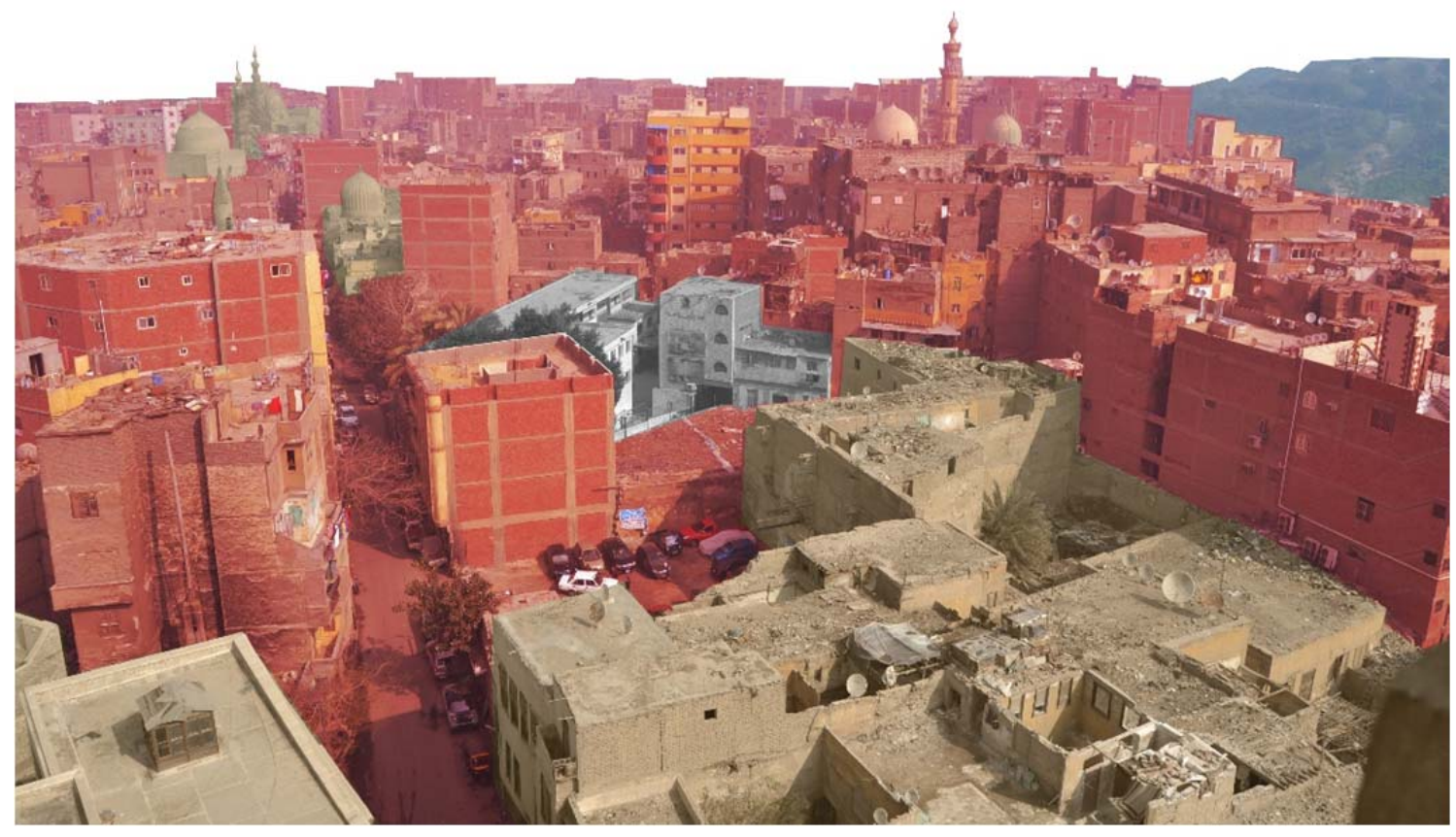

Figure 12. Informal growth pressure on the HUL. (the authors) 


\section{reGREENeration}

The analyses show that the main strength of the site is the uniqueness in its fabric of organic configuration of streets. The presence of historic courtyard structures located in strategic locations is a great opportunity for linking them through corridors. Besides, and according to the field survey, current open spaces in the case study area entail a set of different values. The urban value is distinctive in urban morphology of irregular street disposition, open spaces with different levels of intimacy, richness and heterogeneity in its size, angles and perspectives; qualities that surely characterize a pedestrian oriented urban fabric. In addition, the original system of courtyards defines a balanced relation between the built-up environments and voids.

The architectural value is represented in a number of unique historic buildings (courtyard houses, mosques, Sabil Kutabs, mausoleums, etc), each with a different configuration of the interior spaces and their relation to the exterior to respect privacy and secure circulation for female. The scales of these buildings in relation to their functions are setting a harmonious relationship between the human and the landscape. Building elements such as wind-catchers, lanterns, fountains and others create favourable bioclimatic conditions in the open spaces. That last aspect introduces the environmental value formulated in the passive design of the sit. Courtyards and nonaligned streets have proved to have several bioclimatic benefits as they allow cross ventilation, shadow and natural illumination of open spaces. (El-Habashi, 20I9) The northeast orientation of inner open spaces and the width of the main North-south axis create tunnels of wind flow that avoid heat islands. Vegetation in courtyards serves as habitat for local wildlife.

The historical value is represented in the urban and spatial distribution, with unique patterns and elements that represent different historical periods of urbanism of the city which remained over centuries and still legible. Differences in ground floor level indicating historical layers. The historical values are not only represented physically but also intangibly with the continuity of traditional arts, crafts, rituals and trades. Many of those were modified to meet contemporary mandates, but still rooted with accumulative local knowledge. They create the identity of the place.

Economic value is represented in local traditional crafts although without the wellknown craft guilds. Those crafts links the urban dynamics with the rest of the city. Commercial activities are currently the backbone of the local economy, along with a limited presence of a touristic flow in the area that can be the seed of boosting a new economy if well managed and targeting cultural activities.

Social value is represented in the presence of haras with their social structures that define spatially and administrative open spaces are still preserved. Semi-private spaces allow community encountering, intimacy and sense of belonging. Culture and beliefs determine the use, the character and behaviours of the outside and indoor spaces. The morphology of narrow streets creates closer relationships between the members of the community. 


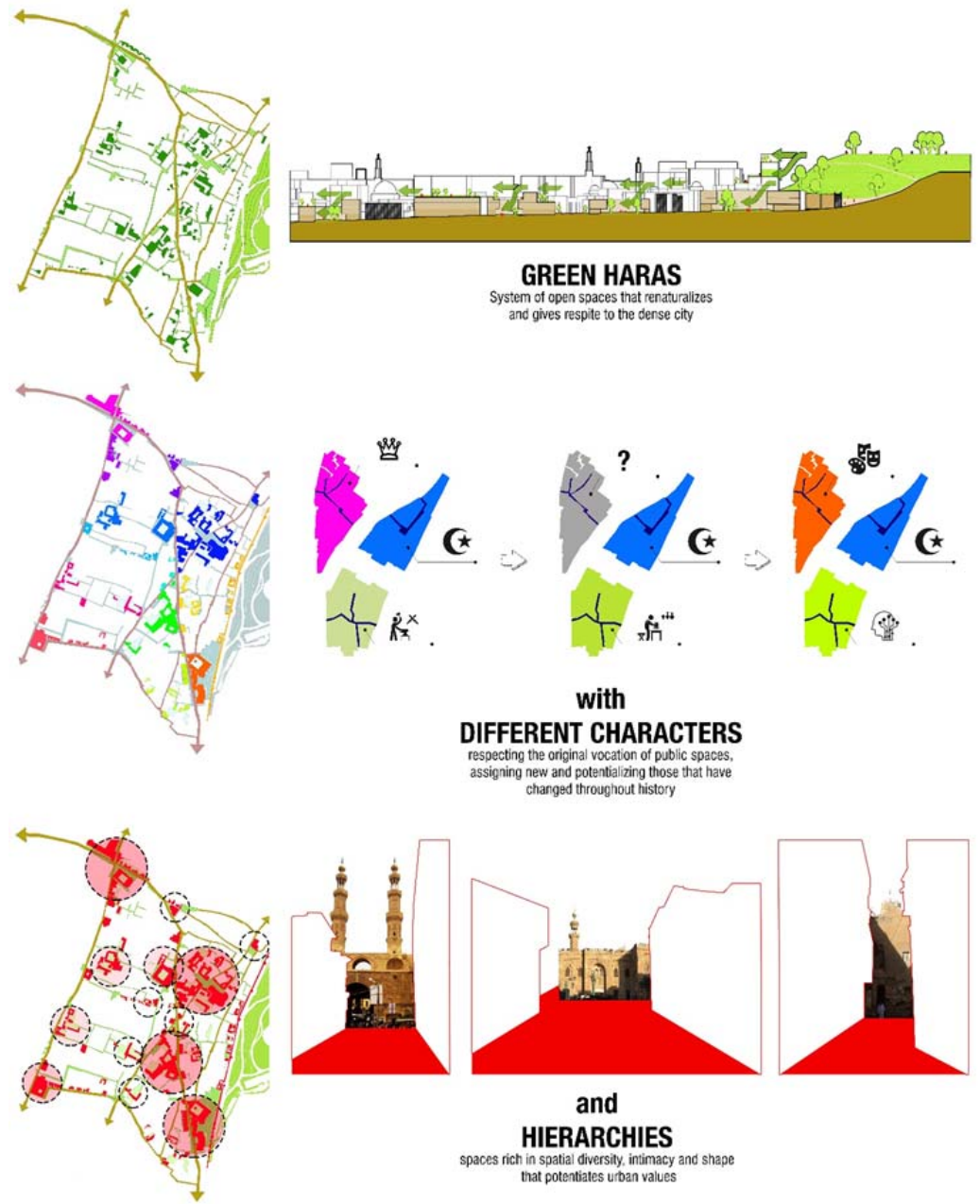

Figure 13. strategy diagrams of the reGreeneration of historic Cairo. (the authors)

The regreenation for historic Cairo is a concept we promote here that consists of a system of open and mostly green spaces with different characters and hierarchies. To re-naturalize and give respite to the dense urban fabric an urban acupuncture can be applied that by the 'green' activate the most valuable but neglected areas. These new corridors should respect the original vocation of the existing open spaces, assigning a new character to those that are not legible and recall those that have been modified throughout history. The configuration of new open spaces is grounded on spatial diversity, heterogeneity, and multiple scales. (Figure 13)

Hence, in accordance with the Valletta charter Principles (VCP) by ICOMOS specific actions are proposed to serve as bases for an urban project which seeks to revitalize the selected area in a holistic approach that includes tangible and intangible values (Figure 14). 


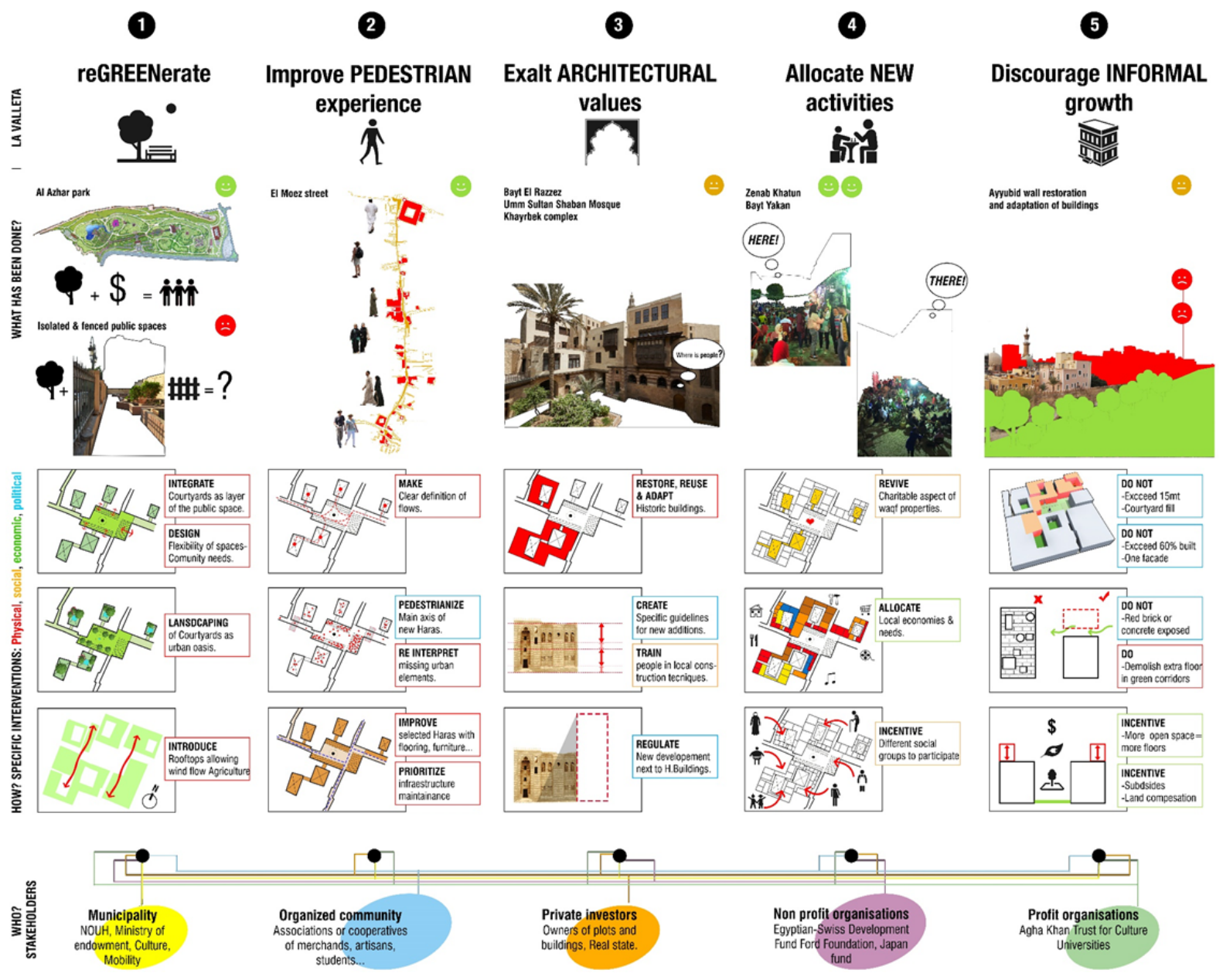

Figure 14. Matrix of guidelines for the area in accordance with the Valletta charter of ICOMOS (The authors).

\section{A. To reGREENerate (VCP - Public space)}

Activate, qualify and enlarge the existing open spaces (Public spaces, courtyards \& Rooftops) interconnecting them into a system which restores the original environmental balance. The map $I$ is an illustration of how this network of open spaces can work (in ground floor level) on the selected area thanks to the application of the following interventions:

- Integrate courtyards as one layer of the public space system. These spaces can provide green areas to the city which is currently unused while generating an income to the owners and has clear limits for a management plan.

- The design of new and rehabilitation of courtyards should be based on the reinterpretation of original landscaping elements, such as fountains, gardens and architectural elements as Maq'aads to create transitions between the private property and the public access. These elements should work as an oasis within the urban fabric. - $\quad$ The design of the public space must be flexible to accommodate community needs and traditions, determined by functions of the ground floor that enclosed it. 
- Introduce complementary and privately own rooftops which are part of the northeast green corridors to allow the wind flow. Urban agriculture, social gathering and renewable energy methods should be promoted and supported.

The regreeneration seeks to extend projects already developed in the area such as AlAzhar park into the dense fabric, respecting the authenticity of the morphology. It is important to mention that due to the entry fees and access control, the maintenance and sustainability of this oasis within the city is possible, strategy that can be replicate into the courtyards.

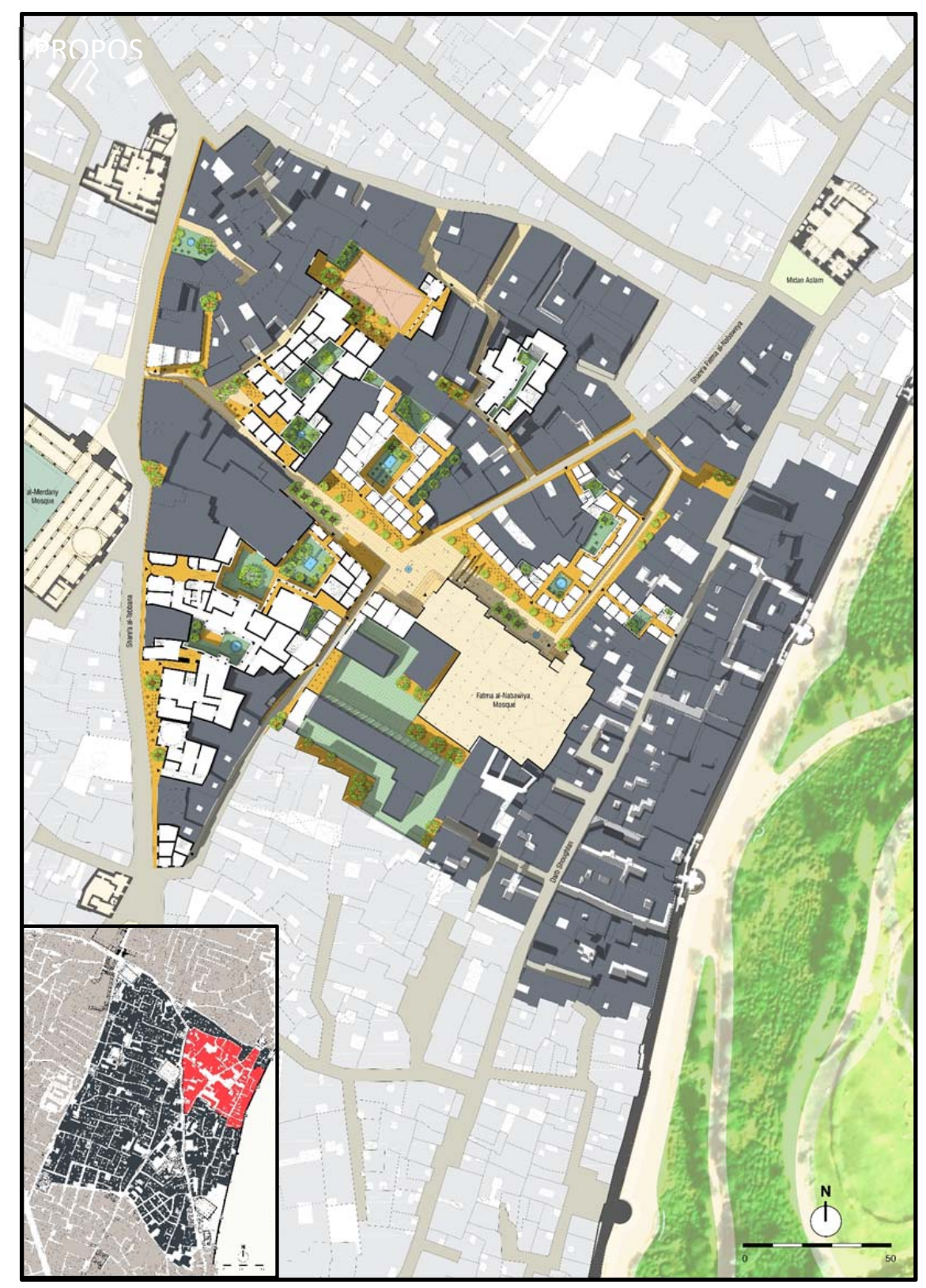

Figure 15. Regreeneration of Hara el-Nabawiya and Bayt Madkour courtyard. (The authors) 


\section{B. Improve the PEDESTRIAN experience (VCP - Mobility)}

Transform historic Haras into axis of pedestrians by allowing permeability in the ground floor of the courtyard buildings. The specific proposed interventions should be oriented to:

- Do a clear definition of pedestrian and car-oriented areas.

- Pedestrianize the main axis of selected Haras.

- Replace motorbike vehicles by bicycle ones and in specific loops.

- Create car flow restrictions.

- Improve selected Hara streets with specific floor design (local textures, geometries, and colours).

- Prioritize the infrastructure maintenance in the main axis of proposed Haras in terms of sewage network, water, public illumination, etc.

- Reinterpret missing urban and architectural features such as gates, cantilevers, Mashrabeias, rhythms, and distribution of facades, small squares, etc.

\section{Exalt ARCHITETURAL values (VCP - Elements to be preserved)}

Celebrate the form and appearance, interior and exterior of the courtyard and historic buildings that enclosed the new system of open spaces, highlighting their structure, volume, style, scale, materials, colours, and ornamentations. Some historic buildings such as Bayt El Razzaz, Umm Sultan Shaban Mosque and Khayrbek complex have been restored the last years. However, most of them are closed due to the lack of coordination between authorities. Thus, complementary actions should be implemented as following:

- Restore, Reuse and Adapt historic buildings with courtyard typologies with high architectural values located in new Haras.

- Create a set of specific guidelines for new additions on historic buildings to respect the scale, find its expression ad keep a balanced relation with the total of the context.

- Train people from the area on local construction techniques. As well as, technical advice by experts or students in the field.

- Regulate new developments next to courtyard buildings with high architectural values in terms of permitted heights, coherence with the urban section, façade openings and rhythms and the balanced relation between built-up areas and open spaces.

\section{Allocate NEW activities (VCP - New Functions)}

Strengthen activities compatible with the historical values of courtyard buildings and promote new functions to the new ones that allow the sustainable development of the community. Zenab Khatun and Bayt Yakan can be considered as successful cases since after proper restoration of the two courtyard buildings, the introduction of uses compatible with the needs of the community, the activation and appropriation of open spaces is considered. Moreover, the property of these cases is private but with public access in some areas that creates an economic or social revenue for the owner while meets the needs of the community. To achieve this goal, it is necessary to: 
- Revive the principles charitable endowment aspect of the property in waqf properties, by assigning functions that benefit the community on the ground floor, especially in those newly restored historic buildings. For a pilot project to empower local community and considers their benefits in development plan see (Yakan, 20l0) - Include local community needs as main uses in the ground floors spaces. (Yakan, 20I0)

- Supplying new residential, workplaces and commercial spaces for the locals

- Introduce new functions that include and encourage other social groups to participate to re-balance the social structural in the area.

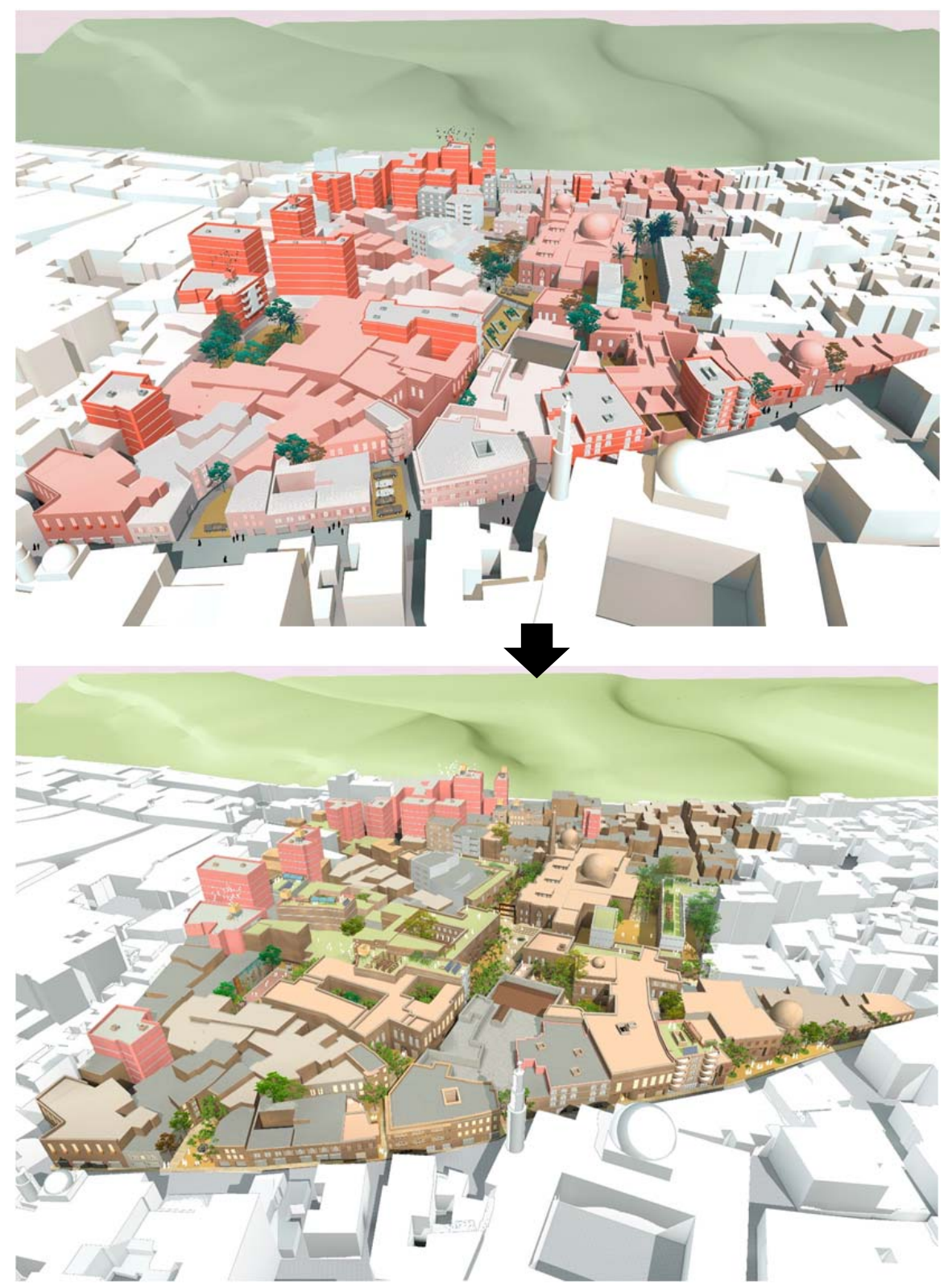

Figure I6: Guidelines applied to the Hara El Nabawiya \& Bayt Madkour courtyard (the authors).

\footnotetext{
${ }^{3}$ Waqf refers here to the charitable endowment system that was known throughout the History of Islam.
} 


\section{E. Discourage INFORMAL growth (VCP - Contemporary architecture):}

Give socioeconomic and collective values to existing buildings and open spaces while creating a clear set of urban rules and incentives to those who comply with them.

During the construction of Al-Azhar park the Ayyubid wall restoration and adaptation of buildings were realized. This project created a paradox since it achieved the opposite effect that has initially sought, since due to the lack of regulations, the garden promoted the residential towers to compete in heights to have a peak towards it. Urban regulations and incentives can control this phenomenon the following manner:

- The original area of courtyards is not buildable.

- New buildings cannot exceed 15 meters high.

- Maximum $60 \%$ of the plot can be the built-up area

- New buildings should respect historic rhythms \& openings or/and do not exceed half of the total surface.

- Redbrick and concrete cannot be exposed in the any façade of a new building.

- If informal buildings are located along proposed Hara's green axis, the extra

floors above the fifth should be demolished and replace by green rooftops.

- Provide incentives for new compatible developments as following: If $40 \%$ of the plot is given to open space the height of additional 2 to 3 floors are allowed if they recess at least 5 meters from the main façade; Subsidies for maintenance of courtyards and Eco-friendly energy (by the municipality); Land compensation in other areas of Cairo as part of an APP (Association of public and private) if stakeholders restore courtyard buildings in historic Cairo.

$$
-
$$

$\begin{array}{llll}\text { CATEGORY OF INTERVENTION } & \begin{array}{l}\text { PRIOR } \\ \text { INTERVENTION }\end{array} & \begin{array}{l}\text { AFTER } \\ \text { INTERVENTION }\end{array} & \begin{array}{l}\text { GROWTH } \\ \text { RATE \% }\end{array} \\ \text { OPEN AREA } & 9823.64 \mathrm{~m} 2 & 12570.24 \mathrm{~m} 2 & 27.95 \\ & & 8157.72 \mathrm{~m} 2 & 19.12 \\ \text {-Public space (Haras) } & 6848.19 \mathrm{~m} 2 & & 48.29 \\ \text {-Courtyards } & 2975.45 \mathrm{~m} 2 & 4412.52 \mathrm{~m} 2 & -7.63 \\ \text { BUILT-UP AREA } & 35975.25 \mathrm{~m} 2 & 33228.65 \mathrm{~m} 2 & \\ \text { \# OF PROPERTIES } & & & 900 \\ \begin{array}{l}\text { INTEGRATED IN SEMI-PUBLIC } \\ \text { ACTIVITIES }\end{array} & 2 & 20 & \\ \begin{array}{l}\text { SURFACE AREA OF PRIVATE } \\ \text { PROPERTIES INTEGRATED IN }\end{array} & 3028.18 \mathrm{~m} 2 & & \\ \text { PUBLIC DOMAIN } & & & \\ \end{array}$

TOTAL AREA (PILOT PROJECT) 45798.89m2

Table I: prior and after proposed interventions in Hara El Nabawiya \& Bayt Madkour (the authors) 
Applying the guidelines of the reGreeneration approach in the Hara Al-Nabawiya and the courtyard of Bayt Madkour, (figures 15-16) the results are summarized in the table above and show that the increment of open areas is considerably high represented in a growth rate of almost $\mathbf{2 8 \%}$. Moreover, the HUL can be read again as a unity, the informal growth can be mitigated and the balance between open and built-up areas is harmonious. As well as, the vegetation became a connector or continuation of Al-Azhar Park as a green element to theoretically re-activate the passivity of the urban fabric. An environmental simulation assessment is envisioned to confirm the ecological benefits. It is also visible, how the concentration of activity is not only along the main streets and its propagation to inner courtyards and roofs.

\section{Discussions}

The research introduces three concepts that are currently being promoted by international institutions concerned with regeneration of historic cities: HUL approach, Sustainable Development, and Green Corridors. It proposes practical means for applicability in Historic Cairo to support the State 2030 Vision that calls for "inclusive sustainable development" and "balanced regional development." (Egypt, 2016) A Historic Urban landscape is not a static set of ancient buildings but a living organism constrained by interdependent layers, ranging from socio-economic, environmental and cultural spheres. Through the main charters related with the safeguarding of world heritage, together with the Valletta principles that are offering practical remedies to achieve sustainable developments in historic contexts, tangible and intangible values shall be preserved and respected while improving quality of life, adapting to the contemporary needs and creating a harmonious relationship with the local ecosystem. This research adopts green corridors strategy as an efficient tool to combine all of the above factors into a balanced ground in al-Darb al-Ahmar in Historic Cairo.

In order to shape those green corridors in al-Darb al-Ahmar, the contemporary setting was studied and analysed. The challenge was to identify the morphological changes in the urban fabric and how the social structure has an important role in the configuration of open spaces. The specific concept of Haras takes vital importance to understand the relation between the inside and outside open spaces. Courtyards are the last stage within a hierarchical organization of public, semi-private and private spaces. Connected open spaces and working as a unity is what shape the territory and contributes to its urban uniqueness. Unfortunately, the conclusions of the analysis showed that this strength is being dramatically disfigured by the main identified threat: the informal highrise growths.

The hypotheses came up as a possible approach to tackle the decadent panorama and strengthen the founded values. This statement is based on giving an economic and social value to the existing open spaces and the historic buildings that enclosed them to create a ripple effect in the activation of other levels as the environmental. The main idea is to test a series of interconnected actions that not only aim to beautify the site but also to mitigate the negative effects of the densification phenomenon as well as contributing to the development of the local community.

This paper concludes that "ReGREENerate" is to re-signify the link between the inside (courtyards) and outside (Haras) through a formula that creates appropriation of open spaces. It offers means to rethink the traditional role of privacy in contexts with lack of 
open space evolving into a more communal oriented that revive the charitable or public vocation of some properties. It then offers practical set of urban guidelines that aim at connecting, qualifying and enlarging open spaces and creating green corridors to enhance the human experience in the territory as well as restore pleasant spaces through urban environmental passivity.

\section{References}

ADAPT, C. (20I5). Green spaces and corridors in urban areas (20I5). [Online]

Available at: https://climate-adapt.eea.europa.eu/metadata/adaptation-options/greenspaces-and-corridors-in-urban-areas

[Accessed Ist November 2019].

Culture, A. K. T. F. (2005). Cairo: Urban Regeneration in the Darb al- Ahmar District. Geneva: Historic cities support programme, Aga Khan press.

Egypt, C. o. M.-A. R. o. (2016). EGYPT VISION 2030. [Online] Available at: http://www.cabinet.gov.eg/English/GovernmentStrategy/Pages/Egypt\%E2\%80\%99sVision2 030.aspx [Accessed 3I December 2019].

El-Habashi, A. \&. H. Y. (2019). "nahw ihya' al-adaa' al-bi'i li-al-biyut zat al-ahwash bi-al-qahira altarikhiya" (towards the revitalization of the climatic performance of the courtyards houses in Historic Cairo). Sharm al-Shaykh, Second International Conference (I Oth Conference on Sustainabe Environmental Development) Menoufia University.

El-Habashi, A. (2012). Safeguarding of Cultural Heritage in Egypt towards a conservation plan for HISTORIC CAIRO, World Heritage Site .., Cairo: Unpublished report submitted to UNESCO's URBAN REGENERATION of HISTORIC CAIRO.

El-Habashi, A. \& all, e. (2018). Assessing the environmental performance of historic Cairo: Preserving values and improving energy efficiency... . Shebin al-Kom: Menoufia University publications.

Gamal, M. (2016). The architecture of home in Cairo, Socio-spatial practice of the Hawari's everyday life. London - New York: Taylor and Francis group.

Hanna, N. (199I). Habiter au Caire Aux XVII et XVIII siecles. Cairo: Institut francais d'archelogie orientale.

ICOMOS (20II). The Valletta principles for the safeguarding and management of historic cities, towns and urban centers. Paris: General assembly.

Jeannet, M. \& Shcuemperlin, N. (20I0). The core of Cairo. A resistance to comprehensive gentrification. Cairo. : Studio Basel, Institut stadt der gegenwart publications.

Mubarak, A. (1987). Al-Khitat Al-Tawfiqiyya. Cairo. Cairo: al-Amiriyya Press.

Rasidi, M., 20I4. The role of green corridors for wildlife conservation in urban landscape: A literature review. Singapur: University Teknologi Malaysia publications.

UNESCO, W. C. H. (20I2). Urban regeneration project for historic Cairo. Cairo: Capmas.

UNESCO, W. H. C. (2013). New life for historic cities: The historic urban landscape approach explained, Paris: The United Nations Educational, Scientific and Cultural Organization (UNESCO).

UNESCO, W. H. C. (20I5). Policy Document for the Integration of a Sustainable Development Perspective into the Processes of the World Heritage Convention. Paris: General Assembly of States Parties to the World Heritage Convention at its 20th session. 
reGREENeration of Historic Cairo

Warner, N. (2005). The Monuments of Historic Cairo, a Map and Descriptive Catalogue. Cairo: American Research Center in Egypt, Inc.

Warner, N. (2006). The True Description of Cairo, A Sixteenth-Century Venetian View. Oxford: Arcadian Library in association with Oxford University Press.

Yakan, B. (20 I0). TCG: Architecture, Conservation \& Heritage Management / Alaa el-Habashi.

Zaky, S. (2009). 19th century houses of old Cairo quarters. the first edition ed. Cairo: The high Council for Culture. 